\title{
David Damoison, Louis-Philippe Dalembert, Vodou! Un tambour pour les anges
}

\section{Paola Ghinelli}

\section{(2) OpenEdition}

1 Journals

\section{Édition électronique}

URL : http://journals.openedition.org/studifrancesi/33851

DOI : 10.4000/studifrancesi.33851

ISSN : 2421-5856

Éditeur

Rosenberg \& Sellier

\section{Édition imprimée}

Date de publication : 1 décembre 2005

Pagination : 688

ISSN : 0039-2944

\section{Référence électronique}

Paola Ghinelli, « David Damoison, Louis-Philippe Dalembert, Vodou! Un tambour pour les anges », Studi Francesi [En ligne], 147 (XLX | III) | 2005, mis en ligne le 30 novembre 2015, consulté le 18 avril 2021. URL : http://journals.openedition.org/studifrancesi/33851 ; DOI : https://doi.org/10.4000/ studifrancesi.33851

Ce document a été généré automatiquement le 18 avril 2021.

\section{(c)}

Studi Francesi è distribuita con Licenza Creative Commons Attribuzione - Non commerciale - Non opere derivate 4.0 Internazionale. 


\title{
David Damoison, Louis-Philippe Dalembert, Vodou! Un tambour pour les anges
}

\author{
Paola Ghinelli
}

\section{RÉFÉRENCE}

DAVID DAMOISON, LOUIS-PHILIPPE DALEMBERT, Vodou! Un tambour pour les anges, Paris,

Autrement, 2003, pp.159.

1 La superbe collection Monde/Photographie des éditions Autrement atteint un de ses sommets avec ce volume consacré au vodou. La lecture de ce livre et la vision de ses images splendides enseigne quelque chose tout en communiquant des émotions. La préface de Laënnec Hurbon indique d'ailleurs un des possibles parcours de lecture de cette œuvre, en débutant avec un texte de 1896 qui exprime «l'inquiétante étrangeté du vodou haïtien» telle qu'elle est, dans certains cas, toujours ressentie. Cette prise de conscience de la méfiance qui persiste à l'égard du vodou est suivie par une analyse détaillé des origines historiques de cette religion, de ses rapports avec l'état haïtien et surtout, de sa fonction sociale et spirituelle auprès des fidèles. Au fil de ces quelques pages, le vodou devient ainsi progressivement une manière d'interpréter le monde, un langage. Moyen de survie pour l'esclave d'antan qui, en la pratiquant, exprimait sa volonté de mémoire et recréait les dimensions spatio-temporelles que les maîtres avaient essayé d'effacer, cette religion est examinée aussi dans le contexte contemporain. En effet, le pouvoir a toujours essayé de s'approprier du culte, qui ne peut être pratiqué sans autorisation que depuis 1987. Mais c'est surtout la partie conclusive du texte de Laënnec Hurbon qui offre enfin une perspective moins ethnologique que symbolique sur le vodou. Non seulement l'auteur esquisse les fonctions remplies par chaque dieu, mais il explique clairement que ce sont surtout les 
rapports des dieux entre eux et avec les humains qui permettent au vodou d'exprimer sa force symbolique et communicative en la transmettant aussi à tous les arts haïtiens.

2 Néanmoins, le texte principal qui constitue ce volume n'est pas la préface mais une contribution narrative de Louis-Philippe Dalembert. Tout en gardant le langage propre à ses fictions et le nom de Salbounda, avec lequel il se réfère d'habitude à Haïti, l'écrivain présente ici un conte pseudo-biographique à la deuxième personne dont le protagoniste adulte, gêné de ne jamais avoir fait l'expérience d'une cérémonie vodou, recherche les raisons de ce manque en évoquant son enfance haïtienne. La série d'épisodes narrés ensuite montre, avec un certain humour, l'omniprésence de cette religion dans le quotidien des haïtiens, qu'ils vivent en Haïti ou ailleurs. Il ne s'agit pas là d'un texte de circonstance, mais d'un long conte qui devrait rentrer à plein titre dans l'œuvre de Dalembert.

3 Plus d'une soixantaine de photos en noir et blanc constituent la dernière et plus vaste section de l'ouvrage. Avec elles, David Damoison a su transmettre une perspective inédite sur la religion vodou, qui respecte les rites et s'émeut des individus. Les espoirs, les souffrances, la fatigue et la dignité des croyants sont tous là, dans ces images d'une force extraordinaire. Le volume dans son ensemble est incontournable pour les littéraires et non qui rencontrent le vodou sur leur chemin. 